\title{
Correction to: Uniaxial experimental study of the acoustic emission and deformation behavior of composite rock based on 3D digital image correlation (DIC)
}

\author{
Jian-Long Cheng ${ }^{1,2} \cdot$ Sheng-Qi Yang ${ }^{1} \cdot$ Kui Chen $^{2} \cdot$ Dan Ma ${ }^{1} \cdot$ Feng-Yuan Li ${ }^{2} \cdot$ Li-Ming Wang $^{2}$
}

Published online: 25 November 2017

(C) The Chinese Society of Theoretical and Applied Mechanics; Institute of Mechanics, Chinese Academy of Sciences and Springer-Verlag GmbH Germany, part of Springer Nature 2017

\section{Correction to: Acta Mech. Sin.}

https://doi.org/10.1007/s10409-017-0706-3

In the original publication of this article, Table 2 is incorrectly published due to the negligence of the author's proofreading. The correct version of Table 2 is provided below:

Table 2 Physical and mechanical parameters of the two materials

\begin{tabular}{llclccc}
\hline & $\begin{array}{l}\text { Uniaxial compressive } \\
\text { strength }(\mathrm{MPa})\end{array}$ & Young's modulus $(\mathrm{GPa})$ & Poisson's ratio & Cohesion $(\mathrm{MPa})$ & Friction angle $\left(^{\circ}\right)$ & Density $\left(\mathrm{kg} / \mathrm{m}^{3}\right)$ \\
\hline Weak rock & 16.44 & 3.60 & 0.23 & 5.21 & 24 & 1627 \\
Hard rock & 68.43 & 23.69 & 0.34 & 18.17 & 40 & 1912 \\
\hline
\end{tabular}

The original article can be found online at https://doi.org/10.1007/ s10409-017-0706-3.

Sheng-Qi Yang

yangsqi@hotmail.com

1 State Key Laboratory for Geomechanics and Deep

Underground Engineering, School of Mechanics and Civil

Engineering, China University of Mining and Technology,

Xuzhou 221116, China

2 State Key Laboratory of Shield Machine and Boring Technology, China Railway Tunnel Group Co., Ltd., Zhengzhou 450001, China 